\title{
EL CONTROL DE LA ACTIVIDAD DE LOS PRESIDENTES DE LAS CORPORACIONES LOCALES
}

351.9: 352

por

\section{Angel Sánchez Blanco}

Departamento de Derecho Administrativo de la Facultad de Derecho de Salamanca

SUMARIO: I. INTRODUCCION.-II. ALTERNATIVAS DE LA NORMATIVA VIGENTE PARA EL CONTROL DE LOS PRESIDENTES DE LAS CORPORACIONES LOCALES: 1. EL CONTROL POLftico. 2. El autocontrol CORPORATIVO. 3. El hetERocontrol ADMINISTRATIVO.-III. LA ALTERNATIVA DEL PROYECTO DE BASES DE REGIMEN LOCAL.

\section{INTRODUCCION}

No es preciso aportar muchos datos para apreciar las posibilidades operativas de los Presidentes de las Corporaciones locales en la determinación de la actividad de Ayuntamientos y Diputaciones provinciales; el amplio cuadro de competencias que tienen atribuidas ofrece adecuada imagen de su relieve institucional y de las dificultades que su posible actividad contra legem puede crear en el momento de su eventual control (1).

(1) Al respecto, el contenido y, en algún apartado, la rotundidad del artículo 116 de la Ley de Régimen local de 1955, planteamiento de que, en esencia, no puede sustraerse el artículo 22 del Proyecto de Bases de la Administración local $(B$. O. de Cortes, 196, I, de 25 de mayo de 1981). 
El texto de la Ley de Régimen local de 1955, en coherencia con el modelo político que lo orientaba, tenía respuestas muy precisas para controlar las situaciones anómalas en las que pudieran incurrir los Presidentes de las Corporaciones locales. En contraste, la incidencia del texto constitucional de 1978 en el texto legal de 1955 y la Ley de Elecciones locales de 1978, en calidad este último de instrumento normativo que constituye en la actualidad el punto de referencia orgánico de las Corporaciones locales, ha propiciado actitudes inhibitorias de la Administración central, que ofrecen un fuerte contraste con los criterios que orientaron la actividad administrativa en situaciones históricas precedentes e incluso una acusada contraposición con el celo mostrado por la Administración central en el control de la actividad de las Comunidades Autónomas (2).

Adecuado reflejo de esta situación se encuentra en resoluciones de la Dirección General de Administración Local, que han considerado derogado el artículo 421 de la Ley de Régimen local, cuyo contexto, según estas resoluciones, era el de una designación del Alcalde por el Gobernador civil o por el Ministerio de la Gobernación, con la consiguiente posibilidad de destitución por el órgano que lo habia nombrado.

Un argumento complementario ha llevado a crear una situación peculiar respecto a los Ayuntamientos, al estimar las resoluciones referidas que, al no existir para el caso de los Alcaldes un precepto paralelo al del artículo 34, 3, de la Ley de Elecciones locales, que prevé la posibilidad de destitución del Presidente de la Diputación por el voto de censura de las dos terceras partes del número de Diputados, y dado el carácter restrictivo, según las resoluciones referidas, que semejantes preceptos deben tener en Derecho, por referirse a instituciones en las que están grandemente implicadas cuestiones de representación popular, obligado es concluir que no existe la posibilidad de destitución del Alcalde por el voto de censura de los Concejales. En este sentido, las resoluciones invitan a pensar, para mayor fuerza del argumento que esgrimen, que ha habido Alcaldes que no han obtenido su cargo por elección de los Concejales, sino por ser el Concejal primero de la lista más votada, lo que equivale a decir que han sido directamente elegidos por los electores del Municipio (artículo 28, 3, c, de la Ley de Elecciones locales), de tal

(2) Como muestra de sensibilidad gubernativa, vid. los datos aportados por CASTELL ARTECHE: «La constatación de la realidad jurídica del hecho autonómico", REDA, número 27 , núms. $637-640$. 
modo que sería un contrasentido que los Concejales pudieran destituir a un Alcalde que no ha sido elegido por ellos.

Los criterios expuestos adquieren mucho mayor relieve cuando se constata el caso de que los hechos implicados, determinados por escritos de denuncia de los propios corporativos, hacen estimar a la Dirección General que pudieran ser considerados como indicios razonables de delito, situación que, sin embargo, no parece generar ninguna medida administrativa, sino la puesta en conocimiento de la Jurisdicción penal competente, bien por los propios miembros de la Corporación, bien por el Gobierno Civil, de tal modo que sería el propio Poder Judicial a quien correspondería tomar medidas precautorias de suspensión de cargo público al iniciarse el proceso $\mathrm{y}$, en su caso, la de dictar sentencia condenatoria de inhabilitación para cargo público. Como reacción subconsciente, que permitiera matizar esta alternativa, la Dirección General concluye estimando procedente la práctica de una visita informativa para el esclarecimiento o prueba de los hechos.

El contraste entre los criterios reseñados y las líneas directrices que orientaron precedentes resoluciones administrativas, en análogas situaciones no muy distantes en el tiempo, es notorio, y obliga a pensar sobre el equilibrio del cambio registrado y sobre la identidad de los fundamentos utilizados.

Finalmente, con el objeto de apreciar la entidad de la problemática suscitada, no puede ser desconsiderada la incidencia que puede tener la remodelación de la figura del Secretario de Corporación local en la configuración de la actividad de los Presidentes de estas Corporaciones, aspecto en el que se registra el importante punto de inflexión constituido por el artículo $4 .^{\circ}$ del Real Decreto-ley 3/1981, de 16 de enero, sobre régimen jurídico de las Corporaciones locales, que, al reducir los supuestos de informe previo del Secretario y, en su caso, del Interventor, a los determinados por el artículo $4 .^{\circ}(3)$, pareciendo querer eliminar la posibilidad de mantener la técnica de las advertencias de ilegalidad (4), relativiza la posibilidad de contraste existente hasta el momento entre las actuaciones corporativas y el continuo asesoramiento en Derecho propiciado por la Ley de Régimen local de 1955 para cualquier actividad de las Corporaciones

(3) Materias con quorum especial y supuestos en los que medien solicitud del Presidente o de un tercio de los corporativos, con antelación suficiente a la celebración de la sesión en que hubiere de celebrarse dicho acuerdo.

(4) Artículo 413.3 de la Ley de Régimen local de 1955. 
locales. La orientación normativa del Real Decreto-ley 3/1981 encuentra consolidación en el Proyecto de Ley de Bases de Régimen local, cuyo artículo 43 toma como referencia directa el tenor del precitado artículo $4 .^{\circ}$ del Real Decreto-ley.

\section{ALTERNATIVAS DE LA NORMATIVA VIGENTE PARA EL CONTROL DE LOS PRESIDENTES DE LAS CORPORACIONES LOCALES}

Con base en las resoluciones preconsideradas, parecen no existir instrumentos que permitan arbitrar técnicas, al margen de las judiciales, para el control de los Presidentes de las Corporaciones locales. En contraste con esta conclusión, es factible la utilización de técnicas de control político y administrativo y, dentro del estricto ámbito administrativo, es factible la operatividad del autocontrol corporativo y del heterocontrol de la Administración central, sin ignorar la posible incidencia del ámbito de competencias de las Comunidades Autónomas.

\section{El control polftico}

La Ley de Elecciones locales de 17 de julio de 1978, en calidad de texto normativo tributario de un sistema político pluralista-parlamentario, vertebrado en base a los partidos políticos, supedita la posesión de la condición de candidato al aval de Partidos o Federaciones de Partidos y, en consecuencia, la posterior retirada de confianza por el Partido o Federación avalante implica, en los precisos términos del artículo 11, 7, de este texto legal, el cese en el cargo del candidato electo. El precepto es coherente con los principios inspiradores de los partidos políticos en el artículo $6 .^{\circ}$ de la Constitución y ofrece una precisa técnica para que, en función de los estatutos de los Partidos o Federaciones y de las concretas previsiones disciplinarias, puedan ser consideradas las actuaciones administrativas irregulares, que impliquen descrédito para estas instituciones o entren en colusión con sus principios inspiradores. La operatividad de Partidos y Federaciones en el control de los candidatos electos que, en su día, avalaron es sólo neutralizada en el caso de candidatos independientes, avalados por Partidos o Federaciones, pero que, al no estar supeditados a disciplina de Partido, no pueden ser objeto 
de remoción por causas vinculadas a la disciplina y coherencia del correspondiente grupo político.

La Ley de Elecciones locales no considera, en el artículo 11, 7, el supuesto de retirada de confianza en el caso de presentación por electores (art. 14, 2,c), exclusión lógica si se estima la falta de carácter institucional de esta técnica de presentación de candidatos y los peligros que presentaría el precondicionar a los electos por el interés de los particulares o las posibles veleidades de los electores que, a nivel individual, los avalaran.

\section{El AUTOCONTROL CORPORATIVO}

Según hemos tenido ocasión de apreciar, la Ley de Elecciones locales sólo regula la técnica del voto de censura para las Diputaciones provinciales (art. 34, 3), en el que se establece la posible destitución del Presidente de la Corporación provincial en el caso de acuerdo corporativo adoptado por las dos terceras partes del número de Diputados.

La carencia de previsión normativa del voto de censura en los Ayuntamientos no permite, sin embargo, llegar a la conclusión de la utilización imposible de esta figura en calidad de técnica de control del Alcalde; ello por varios motivos:

En primer término, por la circunstancia de que, de acuerdo con el tenor literal del artículo 140 de la Constitución, los Alcaldes son elegidos por los Concejales, salvedad hecha del supuesto de los $\mathrm{Mu}$ nicipios bajo régimen de concierto abierto que el artículo $5^{\circ}, 2$, de la Ley de Elecciones locales particulariza en los casos de menos de 25 residentes. Esto implica que, al margen de que la Ley electoral predetermine la primacía del que ocupa el primer lugar en la lista cerrada (art. 28, 3, a y $c$ ), de hecho, tiene que haber una elección de los Concejales para, en último extremo, proceder a la particularización del Alcalde.

El mecanismo descrito, a efecto del tema objeto de consideración, implica que, si los Concejales tienen que asumir la responsabilidad de elegir al Alcalde, tienen la paralela responsabilidad de colaborar con él para el adecuado cumplimiento de las actividades corporativas y de seguir su actividad, en función de los referidos intereses de la Corporación, y, desde una perspectiva más pragmática, en función de la corresponsabilidad corporativa que asumen, en la triple faceta civil, penal y administrativa, prevista por el artículo 412 de 
la Ley de Régimen local, y que puede implicar la asunción de responsabilidades por los Concejales que avalan o consienten las situaciones generadoras de responsabilidad.

Un argumento justifica también la asimilación por los Ayuntamientos de la técnica del voto de censura: la regulación de la situación de "vacante de Alcaldía», prevista por el artículo 28,6 , de la Ley electoral, y cuyos supuestos determinantes, no explicitados por el texto legal, no permiten ser particularizados con carácter sectorial, sino que obligan a considerar, desde la ratio de que donde no hay distinción no cabe distinguir, todos los supuestos generadores de vacancia, y entre ellos el supuesto de voto de censura que, en utilización analógica, con la expresa previsión de esta figura para los Presidentes de Diputaciones provinciales, permita que los corporativos municipales puedan salvar su dignidad y responsabilidad, así como la propia dignidad de la Corporación, utilizando la precisa técnica del voto de censura.

\section{El heterocontrol aDMinISTRATIVo}

Los principios que inspiran a la Dirección General de Administración Local, al dar por derogados todos y cada uno de los supuestos de suspensión o destitución previstos por el artículo 421 de la Ley de Régimen local, provocan una situación de imposibilidad reactiva de la Administración central ante actuaciones de las autoridades locales que puedan encuadrarse en los más radicales supuestos de infracción del Ordenamiento jurídico. El criterio argumental que sirve de fundamento se limita a significar que las facultades de suspensión o destitución que el precepto reconoce a Gobernadores civiles y Ministro de la Gobernación es producto de la designación de los Alcaldes por estas autoridades. Sin embargo, y en implícito contraste con este criterio, el Real Decreto-ley 3/1981, de 16 de enero, sobre régimen jurídico de las Corporaciones locales, abre vías de control y posibilita, en su artículo $8 .^{\circ}$, la suspensión de actos y acuerdos de las Corporaciones a la concurrencia de las circunstancias de que afecten, de modo directo, a materias competencia del Estado y que constituyan infracción de las leyes. No obstante, con una sensible proximidad en el tiempo, será la Sentencia del Tribunal Constitucional número 186/1980, de 2 de febrero, la que sitúe el problema en un contexto institucional, que permita sentir las fuertes implicaciones del artículo 421 de la Ley de Régimen local en el 
contexto de los preceptos constitucionales y, en particular, con los artículos 137 y 140 de la Constitución. Puntos de referencia que conducen al Tribunal a estimar que la autonomía municipal tiene como punto de mira el ámbito de los intereses municipales, que deben ser ejercitados en el marco del Ordenamiento jurídico, de modo que es «la Ley, en definitiva, la que concreta el principio de autonomía de cada tipo de Entes, de acuerdo con la Constitución». En función de este planteamiento, y "como consecuencia del principio de unidad y de la supremacía del interés de la Nación de que el Estado quede colocado en una posición de superioridad, tal como establecen diversos principios de la Constitución, tanto en relación a las Comunidades Autónomas, concebidas como Entes dotados de autonomía cualitativamente superior a la administrativa (arts. 150, 3, y 155, entre otros), como a los Entes locales (art. 148, 1, 2)", el Tribunal llega a la conclusión de que «el principio de autonomía es compatible con la existencia de un control de legalidad sobre el ejercicio de las competencias", excluyendo los controles genéricos e indeterminados, pero admitiendo "los controles de carácter puntual (que) habrán de referirse normalmente a supuestos en que el ejercicio de las competencias de la Entidad local incidan en intereses generales concurrentes con los propios de la Entidad, sean del Municipio, de la Provincia, la Comunidad Autónoma o el Estado" (5).

El Tribunal Constitucional estima, en consecuencia, que el control de la legalidad puede ejercerse en el caso de Municipios y Provincias - dado su carácter de Administraciones públicas- por la Administración del Estado, aun cuando es posible también su transferencia a las Comunidades Autónomas en los términos que expresa el artículo 148, 1, 2, de la Constitución, y, naturalmente, en uno y otro caso, siempre con la posibilidad de control jurisdiccional (6).

En cualquier caso, y como fondo argumental, vertebrador de la decisión, el Tribunal sostiene la idea de que

"la autonomía no se garantiza por la Constitución, como es obvio, para incidir de forma negativa sobre los intereses generales de la Nación o en otros intereses generales distintos de la propia entidad. Por lo que, en estos supuestos, la potestad del Estado no se puede declarar contraria a la Constitución, máxime cuando este principio delimitador de la autonomía se refleja, de forma expresa, en la pro-

(5) $B O E$ de 24 de febrero de 1981, pág. 11, anexo del BOE, II.

(6) Anexo del BOE de 24 de febrero de 1981, pág. 12, I. 
pia Constitución -art. 155- en relación a las Comunidades Autó. nomas».

Por ello, y desde estas precisas construcciones argumentales, el Tribunal Constitucional estima derogado el artículo 421 de la Ley de Régimen local, salvo en el caso de suspensión de Presidentes y miembros de las Corporaciones locales, por período máximo de sesenta dias, en el supuesto de motivos graves de orden público, concepto jurídico que, para su concreción, respecto de la figura de autoridades y miembros de Corporaciones locales, tiene el punto de referencia del artículo $1 .^{\circ}$ de la Ley de Orden Público, al considerar el normal funcionamiento de las instituciones públicas como fundamento del orden público.

Según lo expuesto, se deja sentir la debilidad de los criterios que han orientado el tema del control de las autoridades locales en el ámbito de la Administración central y su lejanía en relación con los criterios del Tribunal Constitucional, que, en virtud del "principio de unidad" y de la "supremacía del interés de la Nación», viene a estimar que la Administración del Estado se sitúa en una transitoria posición de superioridad, al poder suspender temporalmente a los Presidentes o miembros de las Corporaciones locales, remitiendo la decisión última a los Tribunales de Justicia.

\section{LA ALTERNATIVA DEL PROYECTO DE BASES DE REGIMEN LOCAL}

Los criterios orientadores del Proyecto de Ley de Bases de la Administración local permiten detectar aspectos que diferencian el proyecto de sus antecedentes normativos y jurisprudenciales.

En contraste con la Ley de Régimen local de 1955, el Proyecto de Ley está orientado por la premisa de que si en un sistema autocrático y centralista son numerosos los actos de las Entidades locales que son fiscalizados, supervisados o aprobados por la autoridad gubernativa y la Administración estatal puede suspender y aun revocar y anular ciertos acuerdos adoptados por las Corporaciones, en un régimen de autonomía, por el contrario, todas estas facultades fiscalizadoras o de control son excepcionales y, por consiguiente, el control de la legalidad de los actos y acuerdos de las Corporaciones locales corresponde a los Tribunales de Justicia (7). Como punto

(7) B. O. de Cortes, cit., pág. 1319. 
justificativo de la opción tomada, la Exposición de Motivos explicita el artículo 106, 1, de la Constitución, que atribuye el control de la potestad reglamentaria y el control de la legalidad administrativa a los órganos jurisdiccionales. Los criterios base que orientan el Proyecto encuentran ocasión de manifestarse en el párrafo de la Exposición que transcribimos:

«La Ley aplica con escrupulosidad y rigor ambos principios, y contra los actos y disposiciones de las Corporaciones locales que no recaigan sobre materias tributarias o presupuestarias - supuestos en los que se inspira bajo un régimen especial de reclamaciones ante los Tribunales económico-administrativos- no cabrá recurso gubernativo alguno. Tampoco la Administración del Estado podrá ejercer facultades de suspensión, fiscalización, aprobación o control previo; será, pues, imprescindible acudir a los Tribunales de Justicia” (8).

Sin embargo, el Proyecto no es totalmente coherente con las premisas que el texto transcrito contiene, $\mathrm{y}$, con posterioridad al párrafo de referencia, considera lo que denomina «una posibilidad extraordinaria de actuación», que puede implicar bien a la Administración del Estado o bien a las Comunidades Autónomas, en el caso de que una Corporación local «actuara al margen del Ordenamiento constitucional o legal, incumpliendo claramente sus obligaciones $o$ atentando gravemente al interés de España», supuesto en el que el Proyecto establece un procedimiento de intervención que, según la misma Exposición de Motivos, con la concurrencia de las adecuadas garantías, permite al Gobierno o a las Comunidades Autónomas adoptar las medidas precisas para el cumplimiento forzoso de las obligaciones por parte de la Corporación o para la protección del interés general (9).

La matización que este "procedimiento de intervención» implica conecta con los criterios expresados por el Tribunal Constitucional, e incluso son detectables, en los párrafos de la Exposición de Motivos, la inmediata referencia del tenor literal del artículo 155 de la Constitución (10) y de la misma Sentencia del Tribunal Constitucional de 2 de febrero de 1980 (11).

(8) B. O. de Cortes, cit., pág. 1320.

(9) B. O. de Cortes, cit., pág. 1320.

(10) B. O. de Cortes, cit., pág. 1320

(11) $B$. $O$. de Cortes, cit., pág. 1320, II, imprincipium, en conexión con el texto de la Sentencia del Tribunal Constitucional en $B O E$ de 24 de febrero de 1981, pág. 13, $\mathrm{I}$, in fine. 
El principio, concretado en el criterio de no intervención de la Administración central ni de la Administración regional en el ámbito de actuación propio de las Corporaciones locales, que erige a los órganos jurisdiccionales en los únicos guardianes de la legalidad, y la excepción a este principio, materializada en la posibilidad extraordinaria de actuación de la Administración central o regional, cuando una Corporación local actuare al margen del Ordenamiento constitucional o legal, encuentra perfecta y nítida diferenciación en el Capítulo II del Título III, centrado en la suspensión de acuerdos y ejercicio de acciones, y en el Capítulo VII del mismo Título, bajo el epígrafe "Régimen de intervención de las Entidades locales».

En la normativa sobre suspensión se reconoce la inmediata ejecutividad de los actos de las Corporaciones locales, con la excepción de que una disposición legal establezca lo contrario o, en el caso de que, interpuesto recurso, proceda legalmente la suspensión (12). Este principio, que requiere necesariamente la mediación de Ley para su matización, está acompañado de las previsiones procedimentales para que la Administración central y, en su caso, la Administración regional puedan seguir la actividad de las Corporaciones locales, a cuyo efecto se impone la obligación de la Corporación local de remitir extracto de sus acuerdos a la Administración central o regional, con la posibilidad de que éstas puedan solicitar ampliación de los datos referentes a tales acuerdos (13).

En el caso de que sean detectadas infracciones de la legislación del Estado o de la legislación regional, puede ser requerido el Ente local implicado para que revoque, anule o suspenda el acuerdo, y si el requerimiento no es atendido, queda abierta la vía para la impugnación del acto o acuerdo ante la Jurisdicción contencioso-administrativa, lo que posibilita la formalización de suspensión del acto o acuerdo recurrido, debiendo el Tribunal ratificarla o levantarla en el plazo no superior de treinta días (14).

En el supuesto de que sean incumplidas las obligaciones constitucionales y legales o de que se incurra en atentado grave a lo que se denomina el «interés de España» (art. 76, 1), el Gobierno asume el mayor protagonismo que implica el poder requerir directamente al Presidente de la Corporación local para que dé cumplimiento a los imperativos constitucionales y legales, y si no fuere atendido el

(12) Artículo 46-1.

(13) Artículo 46-3 y 4.

(14) Artículo 48. 
requerimiento, el Gobierno es habilitado para «adoptar las medidas necesarias" con la finalidad de obligar a dicha Entidad al cumplimiento forzoso de sus obligaciones o para la protección del interés legal, estableciéndose el requisito procedimental de dar cuenta de ello al Senado. La misma técnica opera en el caso de incumplimiento por las Corporaciones locales de las leyes de las Comunidades Autónomas o cuando implicaren atentado a los intereses propios de éstas, con preceptiva intervención, en este caso, de la Asamblea legislativa de la Comunidad Autónoma.

Ambos puntos de referencia: el régimen normal de suspensión de acuerdos, con la intervención dirimente de los Tribunales de Justicia, y el régimen excepcional, que determina el protagonismo del Gobierno central o de los órganos de gobierno de las Comunidades Autónomas, en los casos de supuesta inconstitucionalidad o de colusión con los intereses propios del Estado o de las Comunidades Autónomas, tienen consecuencias para la valoración de la posición de los Presidentes de las Corporaciones locales desde la perspectiva de la delimitación de su responsabilidad. La primera se materializa en la específica previsión de los requisitos de legitimación para impugnar los acuerdos de las Corporaciones locales, que consideran, junto a la Administración central y a las Administraciones regiona. les, a los Concejales o Diputados provinciales que no hubieren votado favorablemente los acuerdos cuando se estima que éstos incurren en infracción del Ordenamiento jurídico (15), lo cual confiere a los miembros de las Corporaciones un estimable margen operativo que entra en combinación con las previsiones establecidas para los informes de los Secretarios de las respectivas Corporaciones, en función de ilustrar a éstas sobre las implicaciones jurídicas de los acuerdos a tomar, si bien no se puede obviar, según ya señalamos, el recorte sufrido por esta actividad funcionarial en relación con la Ley de Régimen local de 1955.

En segundo lugar, y en referencia a los aspectos procedimentales implicados en el denominado régimen de intervención de las Entidades locales, no puede ser pasado por alto que el requerimiento del Gobierno central o el Gobierno de la Comunidad Autónoma se dirige directamente al Presidente (16), particularización que no se realiza en el procedimiento normal.

(15) Artículo 46-2.

(16) Artículo $76-1$ y 3 
Ambos factores: autonomía de los corporativos e imputación del Presidente por los Gobiernos central o autonómico, implican la implícita particularización del ámbito propio de los Presidentes de las Corporaciones locales, con la paralela delimitación de responsabilidad, en coherencia con el tenor de las amplias competencias que tienen reconocidas Alcaldes y Presidentes de las Diputaciones provinciales (17), y contribuyen a matizar lo que el Proyecto de Bases denomina el Estatuto de Autoridades y Miembros de las Corporaciones locales (18), que tiene como precario motivo dominante las variables simplemente electorales.

(17) Artículo 22, en referencia a los Alcaldes, y artículo 56, en referencia a los Presidentes de Diputación.

(18) Título III, Capítulo III, artículos 51-52. 